\title{
Promoviendo el pensamiento creativo a través de las narrativas visuales y literarias: un estudio de caso en el Grado en Maestro/a de Educación Infantil
}

\section{Promoting creative thinking through visual and literary narratives: a case study in Early Childhood Teacher Training}

\author{
Carmen Franco-Vázquez ${ }^{1}$, Marta Neira-Rodríguez ${ }^{2}$ \\ ${ }^{1}$ Liter21.Universidade de Santiago de Compostela. carmen.franco@usc.es \\ ${ }^{2}$ Liter21.Universidade de Santiago de Compostela.marta.neira@usc.es
}

Recibido: $22 / 6 / 2021$

Aceptado: 25/10/2021

\section{Copyright $($ )}

Facultad de CC. de la Educación y Deporte. Universidad de Vigo

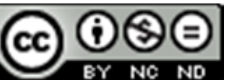

Dirección de contacto: Carmen Franco Vázquez

Facultad de Ciencias de la Educación

Universidad de Santiago de Compostela

Campus Vida, $\mathrm{s} / \mathrm{n}$

15782 Santiago de Compostela

\begin{abstract}
Resumen
Se expone un estudio de caso llevado a cabo con alumnado del Grado de Maestro/a de Educación Infantil de la Facultad de Ciencias de la Educación de la Universidad de Santiago de Compostela La puesta en práctica de acciones compartidas entre diferentes disciplinas permite estimular el pensamiento creativo. De esta forma, la colaboración activa entre el profesorado de áreas diversas redunda en beneficio del alumnado que aprende a plantear proyectos cooperativos de forma práctica. La experiencia se inició en las clases de "Literatura infantil y dramatización". Así, partiendo del autor ya clásico Gianni Rodari, y de su obra Gramática de la fantasía, como primera actividad el alumnado realizó diferentes textos escritos en los que se ponían en práctica diversas estrategias creativas de promoción de la lectura. Estos textos sirvieron de base para el alumnado matriculado en la otra disciplina: "Educación visual y plástica". Esta segunda fase explora las posibilidades de las narrativas visuales tomando como referente artístico artistas e ilustradoras que utilizan el collage para sus creaciones. Finalmente, se analizan las creaciones resultantes y la eficacia de esta metodología.
\end{abstract}

\section{Palabras clave}

Estudio de Caso, Pensamiento Creativo, Maestro de Educación Infantil, Narrativas Visuales, Narrativas Literarias

\begin{abstract}
A case study carried out with students of the degree of Teacher of Early Childhood Education of the Faculty of Education Sciences of the University of Santiago de Compostela is described. The implementation of shared actions between different disciplines allows to stimulate creative thinking. In this way, active collaboration between teachers from different areas benefits the students who learn to desing cooperative projects in a practical way. The experience began in the "Children's Literature and Dramatization" classes. Thus, starting from the now classic author Gianni Rodari, and his book Grammar of fantasy, as a first activity the students wrote
\end{abstract}


different texts in which various creative strategies to promote reading were put into practice. These texts served as the basis for the students of the other discipline: "Visual and Plastic Education". This second phase explores the possibilities of visual narratives, taking as an artistic reference artists and illustrators who use collage for their creations. Finally, the resulting creations and the relevance of this methodology are analyzed.

\section{Key Words}

Case Study, Creative Thinking, Kindergarden Teacher, Visual Narratives, Literary Narratives

\section{INTRODUCCIÓN}

Toda la comunidad educativa resultó muy afectada por las restricciones que la pandemia de la COVID19 impuso al desarrollo normal de la docencia. Docentes de estilos muy dispares tuvieron que alterar la manera de impartir sus materias y hacerse con competencias impensables en años anteriores. Plataformas como Teams, Zoom, Lifesize inundaron nuestras pantallas; recibimos cursos acelerados sobre cómo grabar videos, capturar pantallas, hacer tutoriales, cortar y pegar fragmentos de audio, proteger la propiedad intelectual etc.; conseguimos gadgets tecnológicos como tablets, micrófonos, altavoces o cámaras que se acoplaron a nuestros ordenadores y, además, aprendimos a manejarlos. En este contexto, los docentes tuvimos que reinventarnos y diseñamos estrategias nuevas para seguir avanzando en nuestra tarea de formar al alumnado.

A pesar de ser un alumnado esencialmente vocacional, conviene apuntar que el de las facultades de Educación quizás no sea del todo consciente de "la complejidad y la incertidumbre que se esconde detrás de cada situación educativa" (Susinos y Saiz, 2016, p. 3). Debido al contenido de su titulación, está muy familiarizado con una serie de estrategias educativas dirigidas a otorgarle seguridad y confianza en sus habilidades para enseñar. Ahora bien, eso no significa que estas habilidades aprendidas de forma teórica sean suficientes en todas las situaciones. Por eso creemos que a los alumnos y a las alumnas de las facultades de Educación que estudian los Grados en Maestro de Educación Infantil y de Educación Primaria puede ayudarles para su futura labor profesional el hecho de trabajar en proyectos de carácter interdisciplinar, ya que, además de adquirir conocimientos, aprenden metodologías que son transferibles a las aulas de niveles educativos inferiores.

Los currículums de los planes de estudio en las facultades de Magisterio españolas están organizados en diferentes materias disciplinares (Ciencias, Lengua, Literatura, Expresión Plástica, Música, Expresión Corporal etc.), que insisten más en la importancia de cada didáctica específica que en la posible vinculación con las demás asignaturas. Nosotras consideramos que es importante -y también deseable- diseñar proyectos y experiencias que establezcan cruces entre las disciplinas artísticas. Esta dinámica de trabajo implica propuestas de trabajo interdisciplinar. Además, en relación con este tipo de propuestas colaborativas hace tiempo que "la investigación ha demostrado que las interacciones entre los alumnos, debidamente organizadas por el docente, pueden convertirse en oportunidades de aprendizaje" (Cabrera, 2008).

Aunque este tipo de proyectos no están muy generalizados, existen algunas iniciativas de colaboración interdisciplinar -similares al estudio que presentamos- entre 
el alumnado de Literatura y el alumnado de Artes (Creu, 2006; De Vicente-Yagüe, 2008; Berbel y Capellà, 2014; Botella y Hurtado, 2017). Nuestro proyecto reúne competencias de animación a la lectura, de literatura infantil, de creación literaria, de competencia lingüística, de conocimiento del arte y de diseño de imagen.

Existen muchas razones para trabajar estos conceptos en las aulas de formación de profesorado.

Por un lado, señalamos que "el aprendizaje de la lectura se muestra como un proceso lento, sujeto a una progresión compleja y dependiente de competencias cognitivas y lingüísticas, más concretamente, relacionadas con las capacidades de descodificación y codificación" (Reis da Silva y Martíns, 2016, p. 145). Este proceso de lectura, cuando viaja de la mano de la literatura, va más allá porque, además, nos permite comprender el mundo, entender el contenido, disfrutar de las aventuras, vivir las emociones de los protagonistas etc. (Alonso, 2005; Matos, 2018; Reis da Silva y Martins, 2016). Asimismo:

"A través de la lectura y la escritura se adquieren muchos de los conocimientos necesarios para la formación integral del estudiante; por ello la enseñanza de estos siempre es una actividad central en el ámbito escolar, para fortalecer habilidades y capacidades que generen el desarrollo de procesos de investigación, critica e imaginación, a través de la motivación al proceso lecto-escritor" (Valverde, 2014, p. 100).

Los álbumes ilustrados son un recurso que nos ofrece la oportunidad de ejercitar la lectura visual. En ellos, texto e imagen van elaborando una historia, con diferentes propuestas afectivas y emocionales, que se presentan como un producto artístico (Arizpe y Styles, 2004). Uno de los objetivos que debería tener el profesorado que imparte docencia en Educación Infantil es el de establecer las bases para iniciar el disfrute de la lectura. Este tipo de proyectos que aúnan texto e imagen, narrativas textuales y visuales, resultan muy convenientes y se perfilan como un recurso atractivo para conseguir este fin.

Por otro, la alfabetización visual de nuestro alumnado debe ser algo fundamental en un mundo altamente basado en la comunicación a través de las imágenes, porque algo que no ofrece ninguna duda es la importancia de la cultura visual en el aprendizaje de los niños y de las niñas. Los futuros maestros y maestras tendrán que conocer este tipo de lenguaje para ser capaces de desarrollar la alfabetización visual desde los primeros años de la escolarización, enseñándoles a ver, describir, interpretar y valorar las imágenes. Una buena manera de lograrlo es la de facilitarles oportunidades en las que tengan que abordar problemas de diseño visual (Borges, 2012; Gómez-Díaz y AgustínLacruz, 2010; González Briones, 2011; Martínez Luna, 2014).

Hace ya muchas décadas que Eisner estableció lo mucho que las artes ofrecen a la educación. El Arte tiene que estar presente en la formación de los futuros maestros porque les aporta muchas cualidades, permite formar al alumnado de manera que se transforme en personas más críticas, flexibles, reflexivas e imaginativas. Gran parte de la docencia actual está dirigida a conseguir que toda una clase converja en torno a una única respuesta, como si solo existiese una solución válida para cualquier problema. Las artes, por otro lado, “enseñan a los niños que su sello personal es importante y que hay varias respuestas a las preguntas y varias soluciones a los problemas [...]. En las artes, la diversidad y la variabilidad ocupan un lugar central” (Eisner, 2004, p. 240). 
Muchos docentes, durante estos tiempos presididos por la pandemia, nos hemos cuestionado muchas de nuestras prácticas, se nos ha hecho evidente, de manera urgente e inexorable, otro mundo distinto al actual; en él las palabras de María Novo son muy significativas: "la potencialidad de la aportación artística en la emergencia de otro mundo posible radica no solo en el plus de creatividad e imaginación que aporta, sino también en su capacidad anticipatoria, bien probada históricamente y que ahora se hace más necesaria que nunca" (2017, p. 259).

Finalmente, se señalan los objetivos de esta investigación: 1. Promover la creación literaria de narrativas textuales y visuales; 2. Conocer el grado de aceptación de este tipo de propuesta metodológica colaborativa en el alumnado de Magisterio.

\section{MÉTODO}

Para nuestra investigación, decidimos implementar un estudio de caso, entendido como "una exploración de un "sistema cerrado" o un caso (o múltiples casos) a lo largo del tiempo a través de una recolección de datos detallada, en tal profundidad que involucre múltiples fuentes ricas en contexto" (Creswell, 1998, p. 61). Analizamos "la particularidad y complejidad de un solo caso, llegando a comprender su desarrollo en circunstancias importantes" (Stake, 1995, p. xi). Además, se tuvieron en cuenta distintas medidas para obtener evidencias de los datos: las producciones de narrativa textual, las producciones de narrativa visual, las entradas en los dos foros virtuales, el feedback del alumnado, en su mayoría alumnas, al finalizar el proceso y las anotaciones de las docentes (Yin, 2003). Para realizar este estudio se siguió el esquema siguiente: aproximación a los datos obtenidos, extracción de códigos iniciales, búsqueda de temas, revisión de temas y elaboración del informe (Nowell et al., 2017).

\subsection{Participantes}

Un total de 176 alumnos y alumnas participaron en este estudio realizado durante el curso 2020-21 en el Grado en Maestro/a de Educación Infantil. Más concretamente las asignaturas implicadas fueron "Literatura Infantil y Dramatización", que contaba con 80 personas matriculadas, y "Educación Visual e Plástica: Contextos e Procesos Artísticos", en la que estaban matriculadas 96.

Tanto el alumnado que realizó los relatos, como el que los ilustró, participó de forma voluntaria en el estudio y tenía conocimiento de que sus producciones serían objeto de estudio y formarían parte de una investigación educativa. Este consentimiento informado les aclaró que en ningún momento perdían la autoría, ni la propiedad intelectual de sus producciones. Solamente se negaron a participar cinco personas, que rechazaron que su relato fuese distribuido al alumnado de artes para ser ilustrado, porque ya se habían comprometido a difundir su relato y/o a ilustrarlo por su cuenta.

\subsection{Proyecto interdisciplinar}

La propuesta en la que se basa este estudio implica a dos materias distintas que están ubicadas simultáneamente en el calendario de la titulación de Grao en Maestro/a de Educación Infantil y del Doble Grado en Maestro/a de Educación Infantil y Primaria, 
pero que pertenecen a dos cursos diferentes. Al alumnado de $3^{\text {er }}$ curso, de la materia "Literatura Infantil y Dramatización", se le propuso la creación de un relato breve basado en la técnica creativa "Binomio fantástico" de Gianni Rodari. Se les explicó que deberían idear dos protagonistas cuya asociación resultase de lo más dispar para generar situaciones fantásticas que diesen pie a un texto creativo. Una vez realizada la narrativa textual, los relatos resultantes se distribuyeron de forma anónima entre el alumnado de Artes Plásticas de $2^{\circ}$ curso para ilustrarlos, diseñando una narrativa visual. Como estímulo a la creación de las ilustraciones se le facilitaron imágenes de ilustradores e ilustradoras, artistas famosos y famosas cuyas producciones artísticas estuviesen basadas en la misma técnica que el alumnado tenía que utilizar: el collage con papeles.

\subsubsection{Desarrollo de la propuesta: Clase de Literatura}

La propuesta fue formulada como primera actividad para la totalidad del alumnado matriculado en la asignatura "Literatura Infantil y Dramatización", ofertada para el alumnado del tercer curso del Grado en Maestro/a en Educación Infantil y también para el del Doble Grado en Maestro/a en Educación Infantil y Primaria (cuarto curso).

La realización del "Binomio fantástico" se formuló en el primer mes de clase y fue pensada por la docente para percibir más claramente si las producciones textuales del alumnado podrían caracterizarse como creativas e imaginativas, así como medio para descubrir su nivel de redacción.

Por causa de las medidas COVID establecidas en la Facultad durante ese curso 2020 21 , los tres grupos interactivos/prácticos en los que la actividad fue sugerida estaban divididos en dos turnos, de manera que mientras una mitad de estos tenía clase presencial una semana, la otra mitad trabajaba en docencia semipresencial o teledocencia. A la semana siguiente, los papeles se invertían y el alumnado que había permanecido en teledocencia la semana anterior se incorporaba a las aulas esa segunda semana.

Como primera medida, la docente averiguó en las aulas presenciales y de manera oral qué conocimientos tenía el alumnado sobre el autor italiano Gianni Rodari, sobre su obra Gramática de la Fantasía y sobre la técnica del "Binomio fantástico". A continuación, basándose en los conocimientos previos del alumnado, explicó (o recordó, dependiendo del grupo de alumnos y alumnas) quién era Rodari, habló de su obra y puso algunos ejemplos de los que se podían partir para la realización de esta técnica, haciendo hincapié en la necesidad de buscar dos nombres comunes y en el establecimiento de una relación extraña entre ellos (cuanto más extraña mejor, pues más fantástica sería la historia). Para crear esa unión singular se indicó a las personas participantes que deberían usar una preposición.

Para la realización de la tarea, el alumnado disponía de aproximadamente una hora en el aula presencial, aunque tendría que terminar la actividad fuera del aula si no la terminaba. Asimismo, la docente dispuso en el aula virtual de la asignatura el fragmento de Gramática de la Fantasía correspondiente al "Binomio fantástico" (Rodari, 1999) para aquellas personas que no habían podido asistir al aula presencial o para resolver cualquier duda que surgiese a posteriori; la lectura complementaria podría contribuir a la clarificación y a la revisión del trabajo antes de su entrega por medio de un foro habilitado en el campus virtual. 
Finalmente, en relación con la lengua en la que tendría que estar redactado el texto, conviene indicar que las lenguas oficiales y maternas del alumnado eran indistintamente el gallego y el castellano. Por eso la realización de la actividad no se limitó a una lengua concreta y fueron los participantes los que eligieron libremente una u otra.

\subsubsection{Desarrollo de la propuesta: Clase de Arte}

Como dependíamos de la realización previa del relato, la propuesta fue formulada a mediados del cuatrimestre a la totalidad del alumnado matriculado en la asignatura "Educación Visual y Plástica: Procesos y Contextos Artísticos". Esta materia es obligatoria para el alumnado de segundo curso del Grado en Maestro/a en Educación Infantil y también para el de Doble Grado en Maestro/a en Educación Infantil y Primaria (tercer curso).

Las medidas COVID establecidas en la facultad son las mismas referidas en el epígrafe anterior, aunque en esta materia los grupos interactivos fueron cinco.

Con carácter previo, la docente expuso en una clase telemática todo lo relacionado con la técnica del collage que iban a utilizar, facilitó una recopilación de obras y artistas que trabajan con papeles y avanzó los materiales necesarios para la siguiente clase presencial. Después de conocer la obra de artistas, todas mujeres, que trabajan con papeles, como Hanna Höch, Varvara Stepanova y Sonia Delaunay, e ilustradoras que utilizan la técnica del collage para crear sus narrativas visuales, como Kĕta Pacovská e Iris Samartzi, el alumnado tenía que ilustrar el relato que le había sido adjudicado al azar.

Toda la información, los relatos numerados y la distribución de cada relato al alumnado estuvo a disposición de este en el aula virtual de la asignatura. Para la realización de los collages el alumnado, en su mayoría mujeres, disponía de aproximadamente una hora y media en el aula presencial, aunque, si fuese necesario, tendría que terminar la actividad fuera del aula. Finalmente, se habilitó un foro que servía tanto para subir las imágenes como para comentar cualquier opinión sobre la propuesta.

\section{RESULTADOS}

Al final del curso académico 2020-2021 el alumnado terminó acusando el cansancio acumulado por el importante número de entregas de actividades telemáticas a las que no estaba acostumbrado. No obstante, ni esa fatiga ni las peculiares circunstancias impuestas en la Facultad en cuanto a la presencialidad de docentes y alumnado en las aulas impidieron que los resultados de este estudio de caso fuesen significativos, si bien somos conscientes de que este estudio se limita a un período de tiempo reducido (un curso académico).

Del alumnado matriculado en la asignatura "Literatura Infantil y Dramatización" fueron 67 personas las que participaron elaborando el relato. Por su parte, en la materia "Educación Visual y Plástica: Procesos y Contextos Artísticos" fueron 89 las que realizaron las ilustraciones. Por lo comentado, en el reparto para hacer las ilustraciones hubo que hacer una distribución que obligó a repetir algunos de los textos escritos por el alumnado de tercer curso. Para la mayoría de los alumnos y de las alumnas fue una 
experiencia positiva, pues la calificaron de "gratificante" y "entretenida"; además entendieron que es un buen recurso para utilizar en las aulas de Educación Infantil con los niños.

El alumnado de artes, que cursaba el segundo curso, se mostró, en relación a la propuesta de trabajo colaborativo con estudiantes del curso superior, gratamente sorprendido y valoró positivamente esta cuando se expuso en el aula. También dejó constancia escrita en los foros:

“...destaca el trabajo cooperativo, donde las creaciones de nuestros compañeros de otra materia nos sirven de base para seguir aprendiendo. Así, me gustaría poder aplicar este tipo de proyectos en mi futuro profesional, entendiendo que las materias no son departamentos estancos, sino que se puede trabajar de forma cooperativa entre ellas" (CPD).

"Valoro o feito de que a aprendizaxe sexa globalizada e compartida con outras materias, facendo así unha aprendizaxe máis significativa para nós” (LMM).

"Creo que trabajar de forma conjunta con recursos facilitados por compañeros de otra materia es muy enriquecedor” (MDAT).

Por su parte, con relación a las opiniones del alumnado de "Literatura Infantil y Dramatización" en el momento de ver las ilustraciones que habían sido realizadas para sus textos destacamos:

"Despois de visualizar as diferentes imaxes, penso que están moi completas, destacaron os detalles que tiña cada personaxe: a blusa estampada de Pintileta, o animaliño de cor rosa, o pintabeizos, as onomatopeas da risa... levaron a cabo un traballo moi elaborado, xa que reflectiron totalmente a idea da historia" (LFD).

"Quedei abraiada coas creacións das miñas compañeiras, sen dúbida, souberon plasmar a esencia do meu relato” (MMJ).

Se trata de valoraciones que, a nuestro juicio, reflejan el espíritu de la propuesta que formulamos como docentes.

\subsection{Relatos}

La mayor parte del alumnado matriculado en la asignatura "Literatura Infantil y Dramatización" afirmó desconocer quién era Rodari, su obra Gramática de la fantasía y, por supuesto, nunca había realizado un binomio fantástico. Solamente tenía conocimiento del autor y su obra un número reducido de alumnas que previamente a la entrada en la titulación habían cursado el ciclo superior de FP relacionado con Educación Infantil.

Aunque casi todas las narraciones fueron entregadas en tiempo a través del aula virtual, no todas cumplían las características esperadas, en particular, la selección de dos nombres comunes, unidos por una preposición, entre los que se estableciese una relación extraña que facilitase, en mayor medida, la imaginación y la fantasía.

Una vez finalizada la entrega de la tarea en el campus virtual, se realizó de manera oral una puesta en común en la clase presencial. En ella, además de la lectura de algunos ejemplos, el alumnado manifestó las dificultades a la hora de la realización de la actividad, derivadas fundamentalmente del hecho de tratarse de un ejercicio abierto y creativo al que no está acostumbrado. No obstante, pese a la complejidad de la tarea, el alumnado expuso la necesidad de la realización de actividades de este tipo en las que aprendizaje y diversión van de la mano. 
En cuanto a las creaciones escritas resultantes podrían establecerse diferentes categorías:

\begin{tabular}{lcc}
\hline \multicolumn{2}{c}{ Categorías de los relatos } \\
\hline $\begin{array}{l}\text { Binomios fantásticos } \\
\text { originales/novedosos }\end{array}$ & Binomios fantásticos comunes & $\begin{array}{c}\text { Narraciones más o menos } \\
\text { fantásticas }\end{array}$ \\
\hline
\end{tabular}

Tabla 1. Diferentes respuestas en las creaciones escritas

La primera de estas categorías acoge las creaciones que respondían a lo solicitado por la docente de la materia "Literatura Infantil y Dramatización" y, además, presentaban originalidad en la elección de los nombres o novedad en la relación establecida. La segunda, aquellos textos que, aun respondiendo a lo solicitado, transitan por elecciones y relaciones consabidas y poco originales. Finalmente, la tercera categoría incluye narraciones que no responden a lo propuesto por Rodari para la técnica creativa citada; en ellas los elementos protagonistas seleccionados no ofrecen funciones o relaciones distintas a las esperadas; se parte de personificaciones de objetos o animales o se establecen relaciones lógicas y evidentes que en nada provocan extrañeza, novedad o desvío de caminos ya transitados.

De las tres categorías establecidas destaca el elevado número de ejemplos de la tercera, seguida de aquellos que pueden incluirse en la segunda y de un número muy reducido de textos que se corresponden con la primera.

En cuanto a la lengua empleada en la redacción de los textos, así como a la calidad lingüística y de redacción, cabe destacar que la gran mayoría de las narraciones textuales fueron redactadas en lengua gallega, seguramente por ser esta la empleada en el aula por la docente y la de la mayoría del material por ella facilitado. Se observa un número considerable de textos en los que se han tenido en cuenta las diferentes fases de la escritura (planificación, redacción y revisión), pero también un porcentaje menor, pero significativo, de textos que muestran que no han sido revisados ya que presentan faltas tipográficas y ortográficas graves, del tipo separación del sujeto y predicado mediante coma.

Finalmente, merece la pena destacar un conjunto de creaciones por estar bien escritas; demostrar la capacidad inventiva de las personas que las han elaborado; hacer asociaciones sorprendentes, no evidentes, entre los elementos seleccionados, mostrar un rico vocabulario, etc. Es un buen ejemplo, el fragmento siguiente con una lavadora y un periódico como protagonistas:

“A lavadora pechou a súa porta e empezou a funcionar vendo como o periódico ía dando voltas e como saía tinta volvéndolle a dar un aspecto de novo. Cando terminou fixo o ruído que tanto tempo deixara de facer e a dona sobresaltouse, pois tan só dúas das outras lavadoras estaban ocupadas, polo que se sorprendeu que esa fora utilizada. Mirou un bo anaco de tempo a ver se algún dos clientes ía coller a roupa, pero, conforme pasaban as horas, ninguén foi onda aquela lavadora. Cando ía cerrar acercouse á lavadora $e$ sorprendeuse do que viu, pois, ao abrir a porta, non encontrou roupa, senón un periódico que parecía acabado de saír dunha imprenta. Non daba crédito! Meteu outro para comprobar que aquilo non fora unha brincadeira, pero ao terminar veu como o periódico saía novo.

Ao día seguinte, ao abrir a tenda, colgoulle un cartel á lavadora "Lavadora de periódicos”. Moitos clientes ríanse ao velo, pero todos metían os periódicos para probar si aquilo era certo. Tanta foi a popularidade da lavadora que a lavandería enchíase de xente para ver aquel feito extraordinario" (ARL). 


\subsection{Ilustraciones}

Prácticamente todo el alumnado matriculado en la asignatura "Educación Visual e Plástica: Contextos e Procesos Artísticos” subió las ilustraciones al campus virtual con un comentario sobre las imágenes realizadas, tal y como le fue solicitado. La mitad, además, hizo comentarios personales sobre la actividad. Así, muchas de las personas participantes se refirieron al disfrute que les supuso la realización de la actividad, el empleo de la técnica o a la idoneidad del recurso para trabajar en el aula de infantil. En este sentido son buenos ejemplos las siguientes opiniones:

"Me parece una interesante actividad al servirnos como recurso elaborado por nosotros mismos que podremos utilizar como docentes al narrarles un cuento" (LFD).

"O feito de ter que ilustrar unha historia concreta motiva un pensamento máis profundo e a exploración de diferentes papeis e texturas para combinar. Penso que sería unha actividade moi entretida para levar ás aulas e propoñer ao noso alumnado” (FDA).

Entre las valoraciones destaca también un número significativo de respuestas que aluden a la importancia de trabajar con libertad y de estimular la creatividad como puede explicar el siguiente comentario:

"Nos permite desarrollar nuestra creatividad con gran libertad pero con cierta coherencia para poder representar en imágenes el relato” (PLB).

No obstante, algunos participantes manifestaron dificultades para identificar a los personajes protagonistas de las historias que se le habían asignado, así como a la hora de seleccionar aquellas escenas más significativas. Evidentemente esos inconvenientes responden, como se señaló en el epígrafe anterior, a la incorrecta respuesta por parte del alumnado de tercer curso a la propuesta solicitada y a la no realización en muchos casos de un binomio fantástico. Así, una alumna afirma: "Ao principio custoume un pouco darlle forma á historia xa que esta non establecía dous protagonistas claros" (KSM).

La técnica elegida para ilustrar los relatos fue el collage, técnica, de partida, poco exigente, según nuestro criterio, a nivel formativo para el alumnado, si bien tres personas manifestaron que les suponía dificultad y complejidad. En realidad, el uso de papeles y cartones recortados no comportó especial dificultad; el inconveniente mayor vino dado de la distribución de las formas sobre el espacio compositivo y del diseño de los personajes aprovechando las características de la técnica.

Esta elección del collage estuvo motivada por varias razones: por un lado, es una técnica sencilla de utilizar que no requiere mucha habilidad ni experiencia previa. Por otro, es una técnica que permite componer las formas con bastante agilidad y eso facilita la práctica de una buena ilustración. Además, otra buena razón es la proyección de uso que los papeles tienen en las clases de Educación Infantil, que incentiva la posibilidad de que niños y niñas ilustren sus propias creaciones con formas a partir de papeles recortados.

Finalmente, el uso de la técnica del collage es muy habitual en los álbumes ilustrados para la etapa infantil. Creadores como Leo Lionni, Madalena Matoso, Iris Samartzi, Christian Voltz o Eric Carlé, por nombrar solamente algunos de los más conocidos, emplearon la técnica del collage a la hora de crear las páginas de muchos álbumes que posiblemente estén en todas las bibliotecas escolares.

De todas las ilustraciones entregadas, se puede decir que solamente cinco tienen un nivel de ejecución muy bajo, tres son aceptables y el resto, aunque de diferentes estilos, 
están realizadas con soltura al jugar con las superposiciones de papeles para crear profundidad, alternar papeles lisos con papeles estampados y disponer colores variados con unos contrastes y armonías agradables.

Destacan, de entre todas las presentadas, cuatro narrativas visuales que podrían calificarse de sobresalientes. Por el diseño personalizado de los protagonistas, por la variedad de texturas de los papeles elegidos, por la mezcla contenida de papeles lisos y estampados, por la armonía y coherencia del cromatismo empleado, por la alternancia de planos en las composiciones, por el estilo arriesgado de las formas etc. podrían ser perfectamente ilustraciones de álbumes publicables. Podemos apreciar lo comentado en las Figuras 1 y 2.

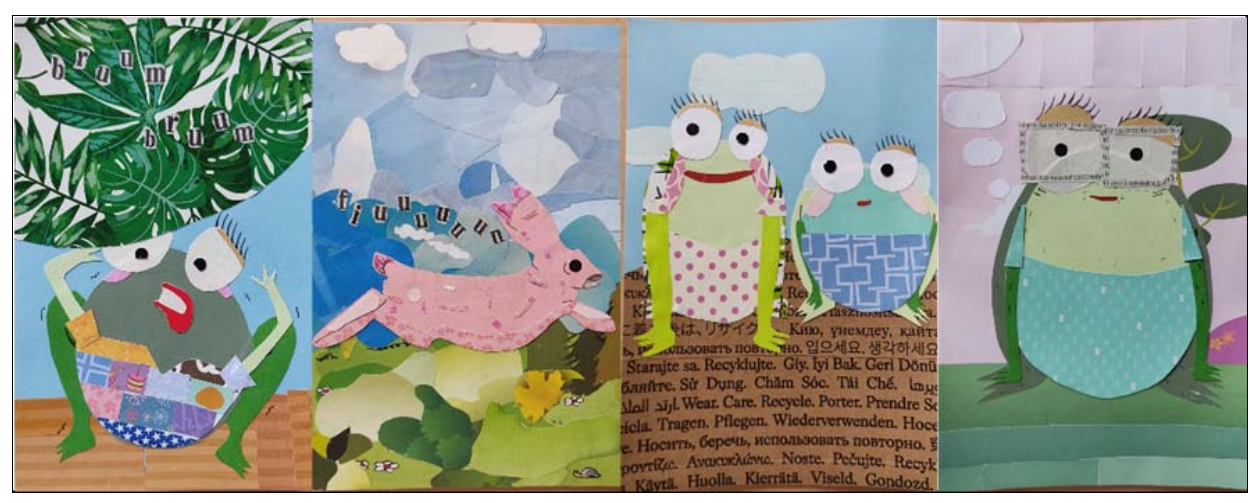

Figura 1. A ra Pintileta

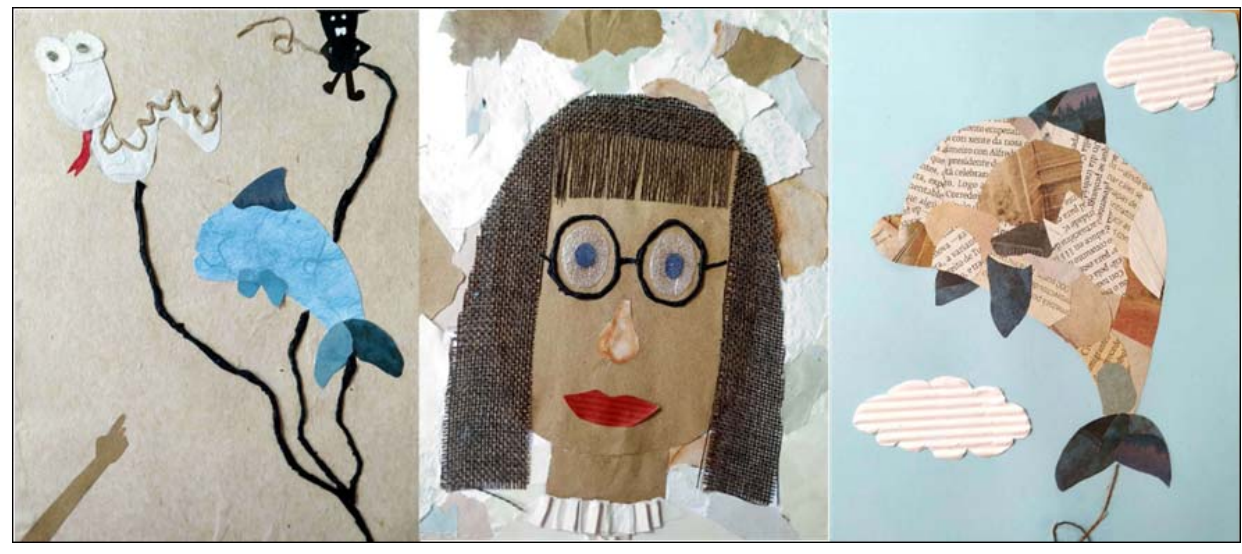

Figura 2. Lara y el delfín

A modo de resumen, son básicamente tres los problemas que nos encontramos en las producciones artísticas analizadas que resumimos en la Tabla 2:

\begin{tabular}{ccc}
\hline \multicolumn{3}{c}{ Principales problemas en las producciones artísticas } \\
\hline $\begin{array}{c}\text { Figuras de los personajes } \\
\text { estereotipadas }\end{array}$ & Infantilismo en las formas & $\begin{array}{c}\text { Escasa competencia en la } \\
\text { composición del plano }\end{array}$ \\
\hline
\end{tabular}

Tabla 2. Diferentes respuestas en las ilustraciones

Con relación al primero, las figuras de los protagonistas, sobre todo de animales, están recortadas siguiendo patrones que el alumnado buscó en Internet. No es frecuente que alumnos y alumnas intenten diseñar los personajes de manera creativa, a pesar de que el profesorado los anime a estilizar y personalizar sus creaciones con 
representaciones figurativas no realistas. Esta cuestión está ligada al segundo problema, la idea de creer que las imágenes destinadas para la niñez tienen que ser de un determinado estilo infantil: figurativo, redondeado, amable y con colores estandarizados. Por último, las composiciones que el alumnado realizó son muy obvias: los paisajes con árboles redondeados, los interiores con una mesa y una ventana, el fondo sin trabajar, las escenas siempre a la misma distancia...

\subsection{Resultados de la propuesta}

Una de las dudas que teníamos antes de iniciar la propuesta en la que se basa este estudio era si las dificultades de relacionar al alumnado de diferentes cursos supondrían más inconvenientes que ventajas. De ahí que una de las preguntas de la investigación fuese conocer el grado de aceptación del alumnado a esta propuesta metodológica. A la vista de los resultados y de las respuestas de alumnos y alumnas en los diferentes foros y en las charlas de las clases presenciales que, aunque en un número muy reducido, se realizaron, podemos colegir que el alumnado ha quedado con una sensación satisfactoria sobre la colaboración entre materias distintas y cursos diferentes, tal y como demuestran las siguientes intervenciones:

"En relación a esta tarefa interdisciplinar, e sendo totalmente sincera, encantoume. Considero moi positivo levar a cabo este tipo de propostas, reforzando os lazos coas compañeiras do resto dos cursos. Ademais, esta tarefa cumpre cos contidos requiridos para a materia de plástica (expresión visual) e de literatura (expresión escrita). Encantoume este feedback” (MMG).

“A miña opinión sobre esta tarefa interdisciplinar, ten que destacar que me pareceu unha técnica moi creativa que sin dúbida porei en práctica no meu futuro coma docente para fomentar a imaxinación na aula, ademais de que foi unha experiencia enriquecedora que engado a miña mochila de futura mestra” (LFD).

Esto nos anima a seguir y a repetir este tipo de metodología interdisciplinar en los próximos cursos.

\section{DISCUSIÓN}

Al organizar este estudio, una de las motivaciones que teníamos era generar una situación en la que alumnado de diferentes cursos pudiese conocer y compartir las creaciones de sus compañeros y compañeras. Creemos que es importante facilitar a nuestro alumnado "la oportunidad de desarrollar esos procesos de reflexión de manera conjunta con otros compañeros que puedan ayudar a comprender las situaciones desde otros marcos de interpretación" (Susinos y Saiz, 2016, p. 4). Al repasar las intervenciones en los foros del alumnado, pensamos que la propuesta presentada ha conseguido una buena aceptación. El alumnado la acoge como una actividad que les aporta ventajas y le encuentra proyección de tipo profesional.

Hemos visto que, cuando se establece una actividad poco dirigida, el alumnado tiene que recurrir a su imaginación y, puesto que este tipo de competencia no está bastante desarrollada, acude a crear figuras estereotipadas y no es capaz de dejarse llevar por ideas originales y disparatadas. Prefieren no arriesgarse usando imágenes clásicas y desarrollando un relato que no tenga estridencias. 
Es evidente la importancia de la imaginación en la educación, aunque no haya muchos estudios que aborden en profundidad este tema (Egan, 1999). La imaginación está en la base de la creación: es una actitud que hay que estimular en el alumnado de Magisterio, ya que es imprescindible en un profesional que se dedique a la docencia (Valverde, 2014). Además, es una cualidad fundamental para despertar el interés por la lectura y la creación artística. Sin embargo, después de esta experiencia nos encontramos con carencias importantes en este sentido, pues las asociaciones que establece el alumnado, en su gran mayoría alumnas, son muy tópicas y la fantasía que manifiestan sus binomios se revela incapaz de establecer desvaríos o uniones disparatadas que den juego a historias diferentes. Asimismo, en lo que al diseño de los collages se refiere, nos encontramos con ilustraciones estereotipadas incapaces de romper con imágenes tópicas sobre animales, paisajes o escenarios.

Al invitar a nuestro estudiantado a crear su propia narración, tanto textual como visual, estamos abandonando una docencia en la que "el profesor da respuesta exacta a las intervenciones de sus estudiantes, para dar paso a estrategias en las que el estudiante debe re-descubrir dichas respuestas" (Cabrera, 2008, p.75). El alumnado carece de recursos, como se vio por la limitada capacidad para fantasear y crear mundos imaginados.

Para la creación de imágenes hace falta tener un conocimiento del lenguaje visual que permita diseñar con soltura figuras con carácter y con estilo propio. De esta forma:

"Es necesario que las producciones infantiles se elaboren de una forma autónoma, es decir, que vayan precedidas de un proceso creador espontáneo, ya que la reproducción de formas previamente elaboradas y mediatizadas por el adulto no ofrece ninguna oportunidad para que los niños establezcan sus propias relaciones con el medio ni para que organicen y articulen a través del lenguaje iconográfico sus pensamientos, sentimientos y sensaciones” (Gutiérrez, 2002, p. 284-285).

El personal docente de Educación Infantil tiene que tener competencias suficientes en alfabetización visual, lo que nos lleva a la necesidad, en las facultades de Educación, de formar alumnos y alumnas para que adquieran también esas competencias: "Contra la escasa formación audiovisual hay que establecer experiencias que suplan esta carencia, que consigan vencer esa inercia que los limita para que acudan al almacén de imágenes de su mente". Con una mayor riqueza de experiencias personales sería más fácil explotar la imaginación ya que "la inventiva surge cuando materializamos verbal o visualmente esos recuerdos que permanecen archivados en forma de imágenes, emociones, palabras o espacios" (Freire, 2018, p. 74).

Podemos concluir, por último, que es necesario insistir en este tipo de propuestas para fomentar la autonomía del personal docente de Educación Infantil a la hora de crear situaciones con niños y niñas. Mientras exista profesorado condicionado por las imágenes o las lecturas preestablecidas se tendrán dificultades para generar proyectos interesantes y creativos en las aulas.

\section{BIBLIOGRAFÍA}

Alonso Tapia, J. (2005). Claves para la enseñanza de la comprensión lectora. Revista de Educación. Número extraordinario, 63-93.

Arizpe, E. y Styles, M. (2004). Lectura de imágenes: los niños interpretan textos visuales. Fondo de Cultura Económica. 
Berbel Gómez, N. y Capellà Simó, P. (2014). Cuentos musicales ilustrados y con soporte audiovisual: una experiencia interdisciplinar en los estudios de Grado de Educación Infantil y Primaria. DEDiCA. REVISTA DE EDUCAÇÃO E HUMANIDADES, 6, 287-294.

Borges, M. (2012). El papel de la ilustración en la alfabetización visual. En H. Barbosa y J. Quental (Eds.), $2^{\text {nd }}$ International Conference Art, Illustration and Visual Culture in Infant and Primary Education (Vol. 1, pp. 268-272). Universidade de Aveiro.

Botella Nicolás, A.M. y Hurtado Soler, A. (2017). Innovación Educativa y renovación de metodologías docentes: Ieducarts y L’Hort 2.0. Innovación Educativa, 27, 205-217.

Cabrera Murcia, E.P. (2008). La colaboración en el aula: más que uno más uno. Cooperativa Editorial Magisterio.

Creswell, J.W. (1998). Qualitative inquiry and research design. Choosing among five traditions. Sage Publications Inc.

Creu Godoy, J. de la (2006). Experiencias interdisciplinares mediante las canciones para niños de Apel·les Mestres. Revista Aula de Innovación Educativa, 151, 26-28.

De Vicente-Yagüe, M.I. (2008). El comparativismo en la educación literaria y musical: propuesta de innovación metodológica. Educatio Siglo XXI, 26, 241-265.

Egan, K. (1999). Fantasía e imaginación, su poder en la enseñanza primaria: una alternativa a la enseñanza y el aprendizaje en la educación infantil y primaria (Vol. 30). Ediciones Morata.

Eisner, E. (2004). El arte y la creación de la mente. Paidós.

Freire, E. (2018). Casas-Mapa. Espazos da Memoria. Elos. Revista de literatura infantil e xuvenil. 5, 73-90.

Gómez-Díaz, R. (2010). La alfabetización visual: retos para un mundo que aspira a la interculturalidad. En R. Gómez Díaz y M.C. Agustín Lacruz (Coords.), Polisemias visuales: Aproximaciones a la alfabetización visual en la sociedad intercultural (pp. 2138). Salamanca.

González Briones, C. (2011). Alfabetización mediática y competencias básicas. Ministerio de Educación.

González-Fernández, N., Ramírez-García, A. y Salcines Talledo, I. (2018). Competencia mediática y necesidades de alfabetización audiovisual de docentes y familias españolas. Educación XX1, 21(2), 301-321.

Gutiérrez Pérez, R. (2002). Educación artística y desarrollo creativo. Arte, individuo y sociedad, $N^{o}$ Extra 1, 279-288.

Martínez Luna, S. (2014). Cultura visual y educación de la mirada: imágenes y alfabetización. Revista Digital do LAV, 7(3), 3-18.

Matos, D. (2018). Literatura Infantil na escola: os contos de fadas nas páginas do livro didático. Elos. Revista de literatura infantil e xuvenil, 5, 137-158.

Novo, M. (2017). El papel de arte y de la educación. Cambiar en tiempos de incertidumbre. En S.M.A.R.T. (Coord.), Caminos hacia la sostenibilidad (pp. 256-261). Acciona.

Nowell, L.S., Norris, J.M., White, D.E. y Moules, N.J. (2017). Thematic analysis: Striving to meet the trustworthiness criteria. International Journal of Qualitative Methods, 16(1), 1-13.

Reis da Silva, S., y Martins, D. (2016). Con letras fanse palabras: achegas para unha caracterización do 'libro-alfabeto' para a infancia. Elos. Revista de literatura infantil e xuvenil, 3, 143-165.

Rodari, G. (1999). Gramática da fantasía. Kalandraka Editora.

Stake, R.E. (1995). The art of Case Study Research. Sage Publications, Inc.

Susinos Rada, T. y Saiz Linares, Á. (2016). Los problemas pedagógicos son mis aliados. El practicum como un proceso de reflexión e indagación colaborativa. Revista de Investigación en Educación. 14(1), 5-13.

Tabernero-Sala, R. (2016). Los epitextos virtuales en la difusión del libro infantil: Hacia una poética del book-trailer. Un modelo de análisis. Ocnos. Revista de estudios sobre lectura. 15(2), 21-36. 
Valverde, Y. (2014). Lectura y escritura con sentido y significado, como estrategia de pedagógica en la formación de maestros. Revista Fedumar Pedagogía y Educación, 1(1), 71-104.

Yin, R.K. (2003). Case study research: Design and methods. Sage Publications Inc. 